\title{
The nursing triage process: a video review and a proposed audit tool
}

\author{
J C Williams, N L Jones, F J Richardson, C Jones, P W Richmond
}

\begin{abstract}
Objective-To review the activity of the nurse triage process.

Setting-The triage room for adults attending the accident and emergency department of the Cardiff Royal Infirmary. Methods-226 triage processes were videotaped over 31 h during July 1994. Activities were subsequently analysed using a specially designed chart.

Results-Areas for improvement in staff communication skills and patient privacy were identified.

Conclusions -The use of video in the triage room allows assessment of the triage process and is a valuable aid to training. Additionally, a potential visual audit tool has been identified

( $F$ Accid Emerg Med 1996;13:398-399)
\end{abstract}

Key terms: triage; video recording

Nurse triage is accepted practice in the United Kingdom. The triage process can take the form of a rapid categorisation but usually incorporates a more detailed assessment including history taking, clinical examination, baseline observations, and first aid.

The triage category is important not only in correctly identifying the priority of the needs of a patient but also because it may have implications in the evaluation of the costs of a department. However this process is rarely assessed.

The video camera has been used successfully to monitor the interview between general practitioner and patients and also for major trauma and cardiac arrest. ${ }^{1-3}$ It does not appear to have been used to study the triage process.

Accident and

Emergency

Department, Cardiff

Royal Infirmary,

Cardiff CF2 1SZ,

United Kingdom

J C Williams

N L Jones

F J Richardson

C Jones

P W Richmond

Correspondence to: Mr P W Richmond.

Accepted for publication 14 May 1996

\section{Methods}

A Panasonic NV-J47B video cassette recorder was used and a MVD CCD colour camera was positioned high up in one corner of the triage room to allow a view of the triage nurse-patient interaction. A plate microphone was placed on the wall above and behind the patient's head. A notice in the triage room informed patients that their interview might be recorded and that they had the right to refuse consent.

Two hundred and twenty six triage episodes were recorded over 31 hours. A chart was designed to aid in the assessment of each triage episode (figure). The recordings were all analysed by one of the authors (JCW) in an attempt to ensure consistency and were all destroyed after review.

\section{Results}

The table shows an analysis of 226 triage episodes over 13 hours 48 minutes $(44.5 \%$ of the total recorded time). The average triage episode time was 3 minutes 42 seconds (range $12 \mathrm{~s}$ to $13 \mathrm{~min} 24 \mathrm{~s}$ ). A score out of 20 was calculated for each triage episode. A mean score of $12.4(62 \%)$ was achieved with a range of 10 to $15(50-75 \%)$.

\section{Discussion}

The use of the video as a teaching aid in general practice has long been established. More recently, it has found a role in the accident and emergency department, although as far as we are aware it has not been used to review the triage process. It is important that triage is carried out speedily, efficiently, sympathetically, and courteously within somewhat arbitrarily defined Patient's Charter limits. ${ }^{4}$ Complaints are often generated by poor communication and discourtesy. ${ }^{5}$

The average triage time in this study was 3 minutes, 42 seconds. Obviously, at busy times in the department, ambulant patient throughput exceeds 15 patients per hour. In this case two nurses triage patients simultaneously and senior medical staff see patients on arrival at particularly busy times.

Video recording of cardiac arrests and major trauma has been going on in the resuscitation room for some time in this department. Despite the initial reservations of staff that fear of personal criticism would adversely affect their performance, this has not happened and all staff have found the process to be nonthreatening and useful. As a consequence of this study, staff involved in triage are now more aware of deficiencies in the triage process and improvements have been made.

The use of video assessment has highlighted problems of patient privacy, communication, and interruptions during triage.

The nurse allocated to triage is also responsible for the reception of stretcher cases and telephone triage outside the triage room. The ambulance reception bay is adjacent to the designated triage room, and the triage nurse also sees and assesses all patients arriving by ambulance. These patients are obviously seen immediately and quickly categorised according to their degree of urgency, thus interrupting any triage processes already in progress. A fuller nurse assessment of these patients is subsequently undertaken within the stretcher area. Any telephone inquiries regarding clinical problems are also all routed through to one telephone located near the triage room and the 


\begin{tabular}{|c|c|c|c|c|c|c|c|c|c|}
\hline & & Woighting & Tringe 1 & Trimoge 2 & Triage 3 & Trioge 4 & Trimos 5 & $\begin{array}{ll}\text { Triage } 6 \\
\end{array}$ & Triago 7 \\
\hline \multicolumn{10}{|l|}{ Stant Timo } \\
\hline \multicolumn{10}{|l|}{ MF Pationt } \\
\hline \multirow[t]{5}{*}{ Pivacy } & Door open/closed & eloced $=2$ & & & & & & & \\
\hline & Imberruptions yos/no & no-2 & & & & & & & \\
\hline & Nures losves & & & & & & & & \\
\hline & Nurse riturns & & & & & & & & \\
\hline & The pation allowe & & & & & & & & \\
\hline \multirow[t]{8}{*}{ Communicalion } & smlio you/no & $y=8=1$ & & & & & & & \\
\hline & Eyo contwet yodno & yosen $=1$ & & & & & & & \\
\hline & throduction by namo you/no & yose-1 & & & & & & & \\
\hline & Introduction by status yos/mo & $y=1$ & & & & & & & \\
\hline & 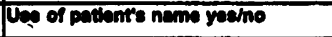 & yesen & & & & & & & \\
\hline & Recoserance yea/no & yeas =1 & & & & & & & \\
\hline & 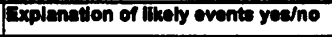 & $y=02$ & & & & & & & \\
\hline & Waithe the givon yea/no & yos $=2$ & & & & & & & \\
\hline \multirow[t]{3}{*}{ Cilnical akfils } & Approperiato History yea/no & yesen & & & & & & & \\
\hline & Approportas Examinestion yoe/no & $y=0-2$ & & & & & & & \\
\hline & Firat ald you/no & $y=0=2$ & & & & & & & \\
\hline \multicolumn{10}{|l|}{ Finteh timo } \\
\hline \multicolumn{10}{|l|}{ Frego thmo } \\
\hline & & & & & & & & & \\
\hline cone & & pour of 20 & & & & & & & \\
\hline
\end{tabular}

Chart for assessment of triage

triage nurse is responsible for dealing with these calls. On average 15 calls per day are received in this department, each taking between one and 10 minutes of the triage nurse's time. We feel that these two additional tasks contributed to the high number of interrupted triage episodes and attempts are being made to rectify this.

Nursing staff introduced themselves by name and status infrequently in this study, but name badges are worn and the named nurse concept adhered to, thus fulfilling the Patient's Charter requirements. Patients were not informed of waiting times in $80 \%$ of cases but it is possible that in a proportion of these there was no significant delay. However, this did highlight areas in which communication could be improved.

Clinical skills were assessed as satisfactory in the majority of cases. If no first aid was required, and therefore not given, this was deemed to be appropriate.

This study identifies the need for a formal audit of the triage process and shows that perhaps a video camera and the use of a chart allows this to be evaluated quickly and

Analysis of 226 triage episodes

\begin{tabular}{llr}
\hline Activity & & Number (\%) \\
\hline Communication & Smile & $203(89.8)$ \\
& Eye contact & $209(92.3)$ \\
& Introduction by name & $14(6.2)$ \\
& Introduction by status & $11(4.9)$ \\
& Use of patient's name & $126(55.8)$ \\
& Reassurance & $79(34.9)$ \\
& Information-following events & $134(59.3)$ \\
Privacy & Information-waiting times & $45(19.9)$ \\
& Closed door & $46(20.3)$ \\
& Interruptions & $135(59.7)$ \\
Clinical skills & Patient left unattended & $82(36.3)$ \\
& First aid & $206(91.2)$ \\
& History & $224(99.1)$ \\
& Examination & $187(82.7)$ \\
\hline
\end{tabular}

effectively. The chart (figure) was designed to allow an analysis of the triage process on reviewing the recording. Patient's Charter criteria and factors relating to privacy, communication, and clinical skills were given a weighted score. A score out of 20 could then be calculated for each triage process. This may be repeated after a period of time to assess improvement, thus allowing the video to be used as an audit tool.

A notice in the triage room indicated that patients could refuse to have their triage process videotaped, but none refused permission. Recent guidelines from the General Medical Council, however, recommend obtaining written permission from patients whose interviews are recorded.

In this department at present patients are triaged into four categories-immediate resuscitation, urgent, acute minor, and non-urgent. Future funding may be based upon triage category rather than simply on the number of attendances, as at present. Thus video recording of the triage process could help provide documentary evidence to support and monitor its accuracy and would also allow interdepartmental audit of the proposed patient triage categories.

1 Cox J, Mulholland H. An instrument for assessment of videotapes of general practitioners' performance. $B M \mathcal{F}$ 1993;306:1043-6.

2 Murray L, McCabe M. The video recorder in the accident and emergency department. Arch Emerg Med 1991;8:1824.

3 Weston CFM, Richmond P, McCabe MJ, Evans RJ, Evans RC. Video recording of cardiac arrest management: an aid to training and audit. Resuscitation 1992;24:13-15.

Department of Health. The patient's charter. London: HMSO, 1991.

5 Hickson GB, Clayton EW, Entman SS, Miller CS, Githens PB, Whetten-Goldstein $\mathrm{K}$, et al. Obstetricians' prior malpractice experience and patients' satisfaction with care. malpractice experience and

6 General Medical Council. Video recording of consultations between doctors and patients, and of other medical procedures, for the purposes of training and assessment. News Review, Winter 1994/1995 issue. 